\title{
Light emission spectra of molecules in negative and positive back discharges in nitrogen with carbon dioxide mixture at atmospheric pressure
}

\author{
Tadeusz Czech ${ }^{\mathrm{a}}$, Arkadiusz Tomasz Sobczyk, and Anatol Jaworek \\ Institute of Fluid Flow Machinery Polish Academy of Science, ul. Fiszera 14, 80-231 Gdańsk, Poland
}

Received 11 March 2015 / Received in final form 5 August 2015

Published online 6 October 2015

(C) The Author(s) 2015. This article is published with open access at Springerlink.com

\begin{abstract}
Results of spectroscopic investigations and current-voltage characteristics of back discharge generated in point-plane electrode geometry with plate covered fly ash layer in a mixture of $\mathrm{N}_{2}+\mathrm{CO}_{2}$ at atmospheric pressure, for positive and negative polarity of the discharge electrode are presented in this paper. Point-plane electrode configuration was chosen in these studies in order to simulate the physical processes occurring in electrostatic precipitator. Three forms of back discharge for both polarities were investigated: glow, streamers and low-current back-arc. Diatomic reactions and dissociation products of $\mathrm{N}_{2}$ and $\mathrm{CO}_{2}(\mathrm{OH}, \mathrm{NO}, \mathrm{CN})$, atoms from fly ash layer $(\mathrm{N}, \mathrm{Ti}, \mathrm{Na})$, free radicals, molecules or ions, which have unpaired valence electrons, and other active species, e.g., $\mathrm{N}_{2}$ (in C,B,A-state), $\mathrm{N}_{2}^{+}$(B) were identified in the discharges by the method of optical emission spectroscopy (OES). The measurements shown that atomic and molecular optical emission spectral lines from back discharge depend on the forms of discharge and the discharge current. In normal electrical discharges, the emission spectra are dominated by gaseous components, but in the case of back discharge, atomic lines belonging to chemical compounds of fly ash were also recorded and identified.
\end{abstract}

\section{Introduction}

Electrostatic precipitator is the most frequently used device for the removal of particles from flue gases from coal-fired power plants. When the sulphur content in the burned coal is at a level below $2 \%$, the resistivity of fly ash deposited on the collection electrode can be higher than $10^{10} \Omega \mathrm{m}$ that can lead to back discharge ignition between the electrodes. Back discharge occurs as an effect of accumulation of electric charge on dielectric layer covering passive electrode. In the case of electrostatic precipitator, such layer is formed by fly ash particles of high resistivity deposited on the collection electrode. When electric charge accumulated on and within the layers reaches a certain threshold level, the electric breakdown, known as back discharge, occurs through the layer. During back discharge, additional ionization processes take place within dielectric layer and close to its surface that provides new ions flowing through the interelectrode space towards the discharge electrode. During back-discharge in electrostatic precipitator, ions of polarity opposite to those emitted by discharge electrode can be extracted from fly ash layer and flow towards the discharge electrode. These opposite ions can be deposited on fly ash particles reducing their charge and decreasing overall collection efficiency of the precipitator.

\footnotetext{
a e-mail: czech@imp.gda.pl
}

Carbon dioxide and nitrogen mixture were chosen for the investigation because they are the main components of flue gases from coal or biomass fired boilers, and knowledge of back discharge formation in these gases is important for electrostatic precipitator operation. Typical content of nitrogen in flue gases is about $80 \%$, carbon dioxide $\sim 15 \%$, oxygen $\leqslant 4 \%$, unburned hydrocarbons $\leqslant 0.1 \%$, and nitrogen oxides $\left(\mathrm{NO}_{x}\right) \leqslant 0.01 \%$. It should also be mentioned that $\mathrm{N}_{2}+\mathrm{CO}_{2}$ mixture is considered as an insulator gas, alternative to strong- greenhouse $\mathrm{SF}_{6}$ [1].

In present studies, optical emission spectroscopy has been used to learn about physical processes occurring in back discharges in $\mathrm{N}_{2}+\mathrm{CO}_{2}$ gas mixture. In such discharge, high-energy electrons can efficiently dissociate, excite and ionise $\mathrm{N}_{2}$ and $\mathrm{CO}_{2}$ molecules and produce chemical reactive radicals $\left(\mathrm{CO}, \mathrm{NO}_{2}, \mathrm{C}, \mathrm{N}, \mathrm{CN}\right)$ or other active species such as $\mathrm{N}^{+}, \mathrm{N}_{2}^{+}$having strong chemical activity [2]. From the measurements of intensity of spectral lines, type of discharge and relative concentration (abundance) of ionized and excited gaseous species present in the discharge and/or volatilized from fly ash layer can be determined. It should be noted that fast ions bombarding fly ash layer also cause dust sputtering from it [3].

Previously, optical emission spectroscopy has been used for the analysis of electrical discharge plasma in various gases by different discharge conditions, and for various types of discharges: pulsed corona discharge, 


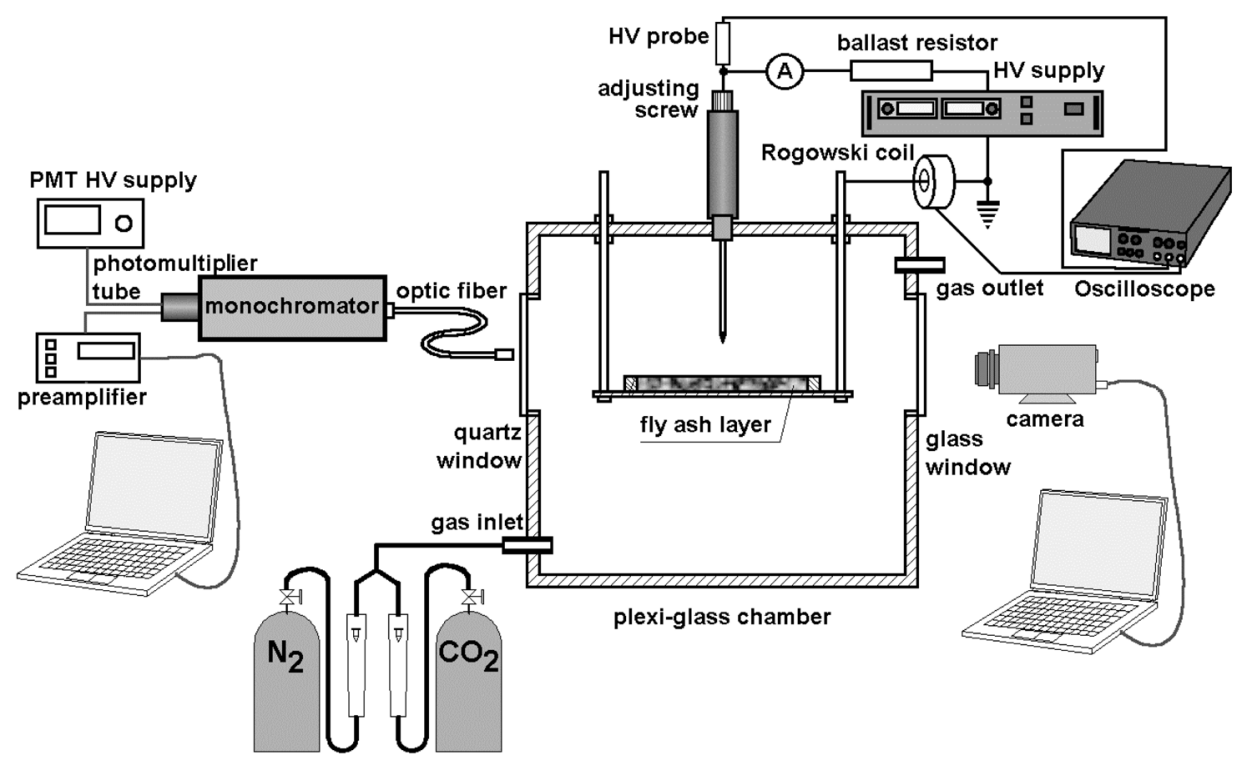

Fig. 1. Experimental setup.

microwave discharge, glow discharge or dielectric barrier discharge [4-10]. The experimental studies of $\mathrm{CO}_{2}$ and $\mathrm{N}_{2}$ dissociation in RF plasma torch at low pressure was investigated by Rond et al. [11] and $\mathrm{Su}$ et al. [12]. These authors measured the energy distribution of electrons in corona discharge and intensity of $\mathrm{N}_{2}$ second positive band. Spectroscopic measurements in air at atmospheric- pressure discharge were also carried out by Shimizu et al. [13], who investigated reaction mechanisms in plasma process. Manabe and Shimazaki [14] investigated the mechanism of surface corona on dielectric plates under negative pulse voltage. Behaviour of molecular compounds in flue gases in microwave induced plasma were studied by optical emission spectroscopy by Timmermans et al. $[7,15]$. Czech et al. have investigated back discharge in air, pure $\mathrm{CO}_{2}$ [5,16-18], and in flue gas simulating mixture [5]. Jasiński et al. [19] presented results of spectroscopic measurements of temperature of neutral gas in microwave torch plasma (MTP) in nitrogen at atmospheric pressure, in air, and in their mixtures with methane. Experimental studies of $\mathrm{CO}_{2}$ dissociation in $\mathrm{RF}$ plasma torch were carried out by Rond et al. [11] in order to learn about the influence of discharge power on plasma characteristics. Electrical discharges, including back-discharge, in $\mathrm{N}_{2} / \mathrm{CO}_{2}$ mixture, the main compounds of flue gases, at normal pressure and ambient temperature have hitherto not been studied.

In this paper, current-voltage characteristics of back discharge, and spectroscopic analysis of ionisation and excitation processes of gaseous molecules in back discharge are presented. The effect of $\mathrm{CO}_{2}$ and $\mathrm{N}_{2}$ percentage in $\mathrm{CO}_{2}+\mathrm{N}_{2}$ mixture on back discharges in point-plane electrode geometry has been studied. For the purpose of this paper the spectroscopic data were taken from the books of Pearce and Gaydon [20], and Striganov and Sventickij [21]. The main aim of this work is to understand the mechanisms that govern the production of active species in back discharge. This research will help to better understand the back-discharge processes occurring in electrostatic precipitators, which decrease their collection efficiency.

\section{Experimental}

A schematic of experimental setup used in these investigations is shown in Figure 1.

The discharge chamber, used also in previous experiments $[5,16,17]$, was made of PMMA, in the form of cube of inner edge of $160 \mathrm{~mm}$. The discharge was generated from needle of diameter of $1.5 \mathrm{~mm}$ and cone angle of about $15^{\circ}$ facing perpendicularly stainless steel plate. The distance between the tip of needle and the plate was $20 \mathrm{~mm}$. The needle electrode was at high potential while the plate was grounded. The plate was covered with fly ash layer of thickness of $5 \mathrm{~mm}$, collected from an electrostatic precipitator. The discharge was generated in nitrogen and carbon dioxide mixture at various proportions, at normal pressure, and at ambient temperature. Both gases were purchased from Messer-Polska. The rest gases in this mixture were $\mathrm{O}_{2}, \mathrm{CO}$ and $\mathrm{H}_{2} \mathrm{O}$ (at a level of $100 \mathrm{ppm}$ total). The flow rate of gas flowing through the discharge chamber was controlled by flow-meter (Metal Chem, Gliwice). The electrodes were supplied from a high voltage DC source SL300W/30kV/PN (Spellman) with a ballast resistor of $5 \mathrm{M} \Omega$ connected in series with discharge electrodes, in order to stabilize the discharge current. The supply voltage was changed from $5 \mathrm{kV}$ to $30 \mathrm{kV}$, by keeping other corresponding parameters constant.

The emission spectra were measured by means of spectrometer SPM-2 of resolution of about $0.5 \mathrm{~nm}$ for the width of slit of $1 \div 0.5 \mathrm{~mm}$, and a grating of 1300 grooves per $\mathrm{mm}$. The light from the discharge was transmitted to the spectrometer via a quartz optical fiber, which was pointed to the plasma column either on fly ash 


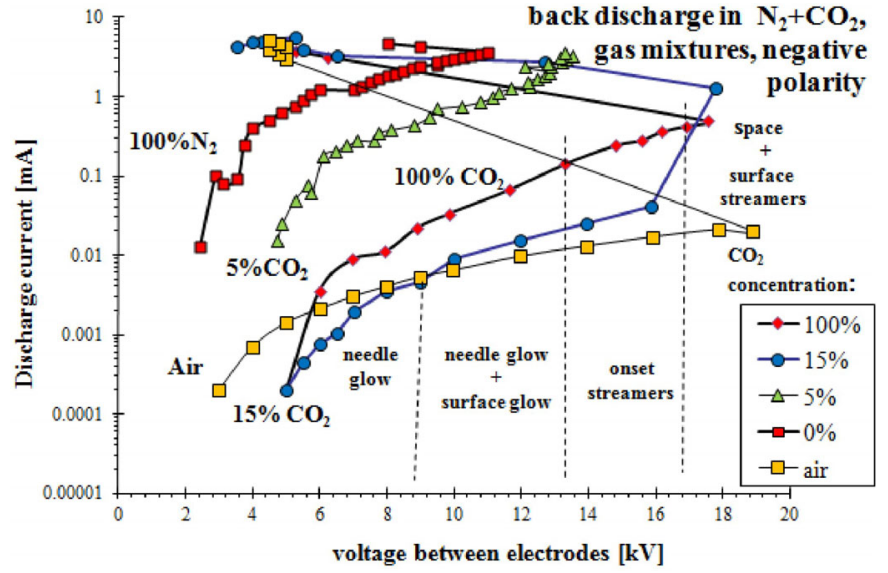

Fig. 2. Current-voltage characteristics of back discharge in $\mathrm{N}_{2}+\mathrm{CO}_{2}$ gas mixtures for different $\mathrm{CO}_{2}$ to $\mathrm{N}_{2}$ raatios, at atmospheric pressure, for negative polarity of the discharge electrode.

layer or the tip of needle electrode. Photomultiplier tube R375 (Hamamatsu) and signal preamplifier unit C7319 (Hamamatsu) were used to detect optical signals from the spectrometer, and the data were transmitted to PC. A glass window of diameter $58 \mathrm{~mm}$ was mounted to the chamber wall in order to take photographs of the discharge. The discharge current, was measured with moving coil ammeter of appropriate range connected between the needle electrode and supply unit at high voltage side.

\section{Results}

\subsection{Current-voltage characteristics}

Current-voltage characteristics of back-discharge for negative polarity of the needle electrode, for various values of $\mathrm{N}_{2}$ to $\mathrm{CO}_{2}$ ratio are presented in Figure 2. For comparison, current-voltage characteristics of the discharge in air are also shown in this plot. For increasing voltage between the electrodes, the following discharge modes can be distinguished from visual observation:

\section{Needle glow}

For lower voltages, only bright points (glow) surround the needle tip, indicating ionisation processes in this region. The current is of the order of tens of microamps. At normal pressure, the frequency of electron-molecule collisions increases with increasing voltage, but the gain of energy of electrons between collisions is sufficiently high to sustain gas ionization. Needle glow + surface glow

Electrons and negative ions produced in the ionization region close to the needle tip drift in the electric field and are deposited onto the dielectric surface, forming a surface charge on it. The magnitude of this charge becomes sufficiently high to promote gas ionization at certain points at this surface, and surface glow appears. When the voltage is further increased, the surface charge increases due to increasing ionic current from the discharge electrode, and the electric field through the layer becomes sufficiently high to cause many breakdown points through the layer, appearing as bright spots. Bright glow indicates excitation and de-excitation and ionisation/recombination processes in these points. The vibrational energy levels (bands) of $\mathrm{N}_{2}$ and $\mathrm{CO}_{2}$ can be easily excited due to electron collisions in this type of discharge, but direct electron excitation of the $C^{3} \Pi_{u}$ and $B^{3} \Pi_{g}$ triplet states appears only near sharp electrode. The mean electron temperature obtained using zero-dimensional Boltzmann solver BOLSIG $+[22]$, for the $E / N$ ratio as in plasma column, was the maximum for pure $\mathrm{N}_{2}$ and was about $T_{e}=0.2 \mathrm{eV}$. For other values of $\mathrm{CO}_{2}$ to $\mathrm{N}_{2}$ ratio investigated, the mean electron temperature was about $T_{e}=0.03 \mathrm{eV}$, and the main energy loss fractions was for vibrational $\mathrm{CO}_{2}$ excitation. It should be noted that unlike normal corona discharge, the current of back discharge does not increases monotonically with the voltage magnitude increasing. When ionization processes begin at dielectric layer, the current increases steeply, almost two orders of magnitude, due to charge carriers of positive polarity (opposite to those from the discharge electrode), are generated in those bright spots on the layer. This phenomenon is characteristic of this gas mixture and has not been observed in the discharge in air (cf. Czech et al. [16]).

\section{Streamers}

The onset-streamers discharge mode starts at a voltage of about $20 \mathrm{kV}$, for these specific experimental conditions. When electric field is sufficiently high, pre-onset streamers develop from the point electrode and form a faint unstable filament along the gap, which connects the tip of needle electrode with dielectric layer. With supply voltage increasing, one of these onset streamers from the discharge electrode develops into breakdown streamer or spark, expanding from the needle tip through dielectric layer towards plate electrode. Total energy dissipated in the discharge increases strongly with increasing discharge current. The excitation energy of $\mathrm{CO}_{2}$ and vibrational energy of $\mathrm{N}_{2}$ molecules can be effectively transferred between them in collisions. The number of streamers in a unit time increases with the voltage increasing. For negative polarity, each streamer bridges the entire interelectrode space, and stretches between the needle tip and a spot formed on the dielectric layer. The streamers can further develop into arc discharge when supply voltage and discharge current reach sufficiently high values.

\section{Back-arc}

During arc discharge, the discharge current increases rapidly to a couple of milliamps (1-8 mA) (Fig. 2), and its magnitude is only limited by the ballast resistance $R$. Back arc discharge appears as a bright plasma column, of a couple of millimetres in diameter, which permanently connects the discharge electrode (needle) and one breakdown point (crater) in dielectric layer. For low-current back-arc discharge, thermal ionisation 


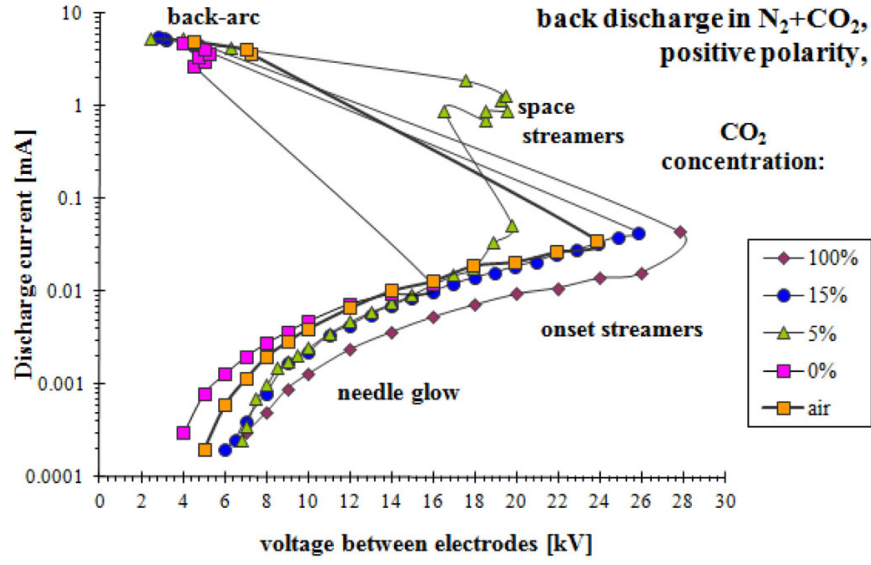

Fig. 3. Current-voltage characteristics of back discharge in $\mathrm{N}_{2}+\mathrm{CO}_{2}$ gas mixtures for different $\mathrm{CO}_{2}$ to $\mathrm{N}_{2}$ ratio, at atmospheric pressure, for positive polarity of the discharge electrode.

takes place in the interelectrode space and in the crater formed in dielectric layer.

For positive polarity (Fig. 3) the following discharge modes can be observed:

\section{Needle glow}

When discharge current is of the order of magnitude of a few microamperes, initially many faint breakdown points appear close to the needle tip and on the surface of layer, similarly to the discharge at negative polarity.

\section{Streamers}

Unlike negative corona, for positive polarity, besides space streamers, also surface streamers are created as luminous channels at the dielectric layer surface, presumably because of negative ions supplied from breakdown points at the layer. The space streamers develop in the form of filaments from some points at dielectric layer, towards discharge electrode. As a result, space streamers become more luminous and the discharge current is higher and much more unstable than in negative polarity discharge. A large number of ions are emitted from many breakdown points occurring on dielectric layer. The transition of space streamers to back-arc discharge takes place at higher voltages than for negative polarity.

\section{Back-arc}

Similar to negative polarity, the discharge current increases steeply to 1-8 mA (Fig. 3), and its magnitude is only limited by the ballast resistance $R$. Back arc discharge appears as a bright plasma column, of a couple of millimetres in diameter, which, unlike negative polarity, is divided into two parts separated by a dark space.

\subsection{Effect of $\mathrm{CO}_{2}$ and $\mathrm{N}_{2}$ concentration}

This section considers the influence of binary $\left(\mathrm{N}_{2}+\mathrm{CO}_{2}\right)$ gas mixture composition on current-voltage characteristics of back discharge. For negative polarity of the needle electrode, even a small amount of $\mathrm{CO}_{2}$ in $\mathrm{N}_{2}$ causes a sharp decrease in discharge current, for the same supply voltage, to magnitude close to that in pure carbon dioxide. The decrease in discharge current results from $\mathrm{CO}_{2}$ as electron attaching gas [1] and the presence of $\mathrm{CO}_{2}$ dissociation products $\left(\mathrm{CO}\right.$, atomic $\mathrm{O}$ and molecular $\left.\mathrm{O}_{2}\right)$ which are also electronegative, which reduces the number and energy of free electrons by their attachment after collision. Goldman [23] explained this phenomenon by the formation of negative space charge sheath in the vicinity of sharp electrode. This space charge increases the electric field close to the tip of needle (ionization zone), but decreases downwards in the interelectrode space (drift zone), to a value too low for streamers formation.

Higher concentration of $\mathrm{CO}_{2}$ in $\mathrm{N}_{2}$, above a certain level, does not change the discharge current significantly. Due to collisions between $\mathrm{CO}_{2}$ with $\mathrm{N}_{2}$ molecules, the excitation energy of $\mathrm{CO}_{2}$ can be easily transferred to $\mathrm{N}_{2}$ and vice versa, because $\mathrm{CO}_{2}$ excitation level is close to the vibrational level of $\mathrm{N}_{2}$. The voltage of initiation of back discharge increases with increasing $\mathrm{CO}_{2}$ concentration, for example, it is $2.5 \mathrm{kV}$ for $0 \% \mathrm{CO}_{2}, 4.5 \mathrm{kV}$ for $15 \%$ $\mathrm{CO}_{2}$, and $\leqslant 5 \mathrm{kV}$ for $100 \% \mathrm{CO}_{2}$.

Unlike negative polarity of the discharge electrode, for positive polarity, the discharge current does not differ much with varying concentration of $\mathrm{CO}_{2}$ (cf. Fig. 3). Whereas for negative polarity, the current span over three orders of magnitude for the same supply voltage with variations in $\mathrm{CO}_{2}$ concentration, for positive polarity, it remains within an order of magnitude. Additionally, all current voltage characteristics are close to that for air. The only difference is streamer to arc transition at lower voltages, for low $\mathrm{CO}_{2}$ concentration. This can be explained by the process of relative energy losses by radiation emission of $\mathrm{CO}_{2}$.

\subsection{Fly ash elemental composition}

The goal of this section is to investigate the discharge processes in $\mathrm{N}_{2}+\mathrm{CO}_{2}$ mixture at atmospheric pressure with the method of optical emission spectroscopy. Unlike discharges in gases between two clean electrodes, back discharge characteristics and emission spectra depend not only on gas composition and electrodes geometry but also on electrical properties of dielectric layer covering passive electrode, and on elemental and molecular composition of this layer. For this reason, the elemental composition of fly ash used in these investigations has been determined using EDS spectroscopy method.

Elemental analysis of fly ash sample collected from third stage of electrostatic precipitator in coal fired power plant supplied with polish bituminous coal is shown in Figure 4, and summarized in the form of column plot in Figure 5. The content of each element is expressed in atomic percent normalized to total number of counts for all elements. As can be expected, silicon is the main element in fly ash sample, and its content is in the range of $12-$ 14 at.\%. The next most abundant element is aluminium (11 at.\%). Carbon content is about 5 at.\%. The most 


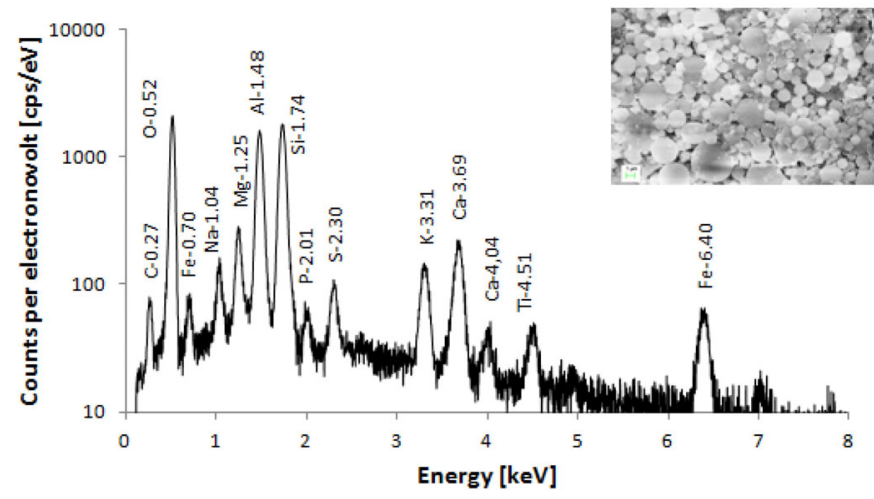

Fig. 4. EDS spectrum of fly ash, indicating its elemental composition. Inset: SEM microphotograph of fly ash particles (magnification: $\times 10000$ ).

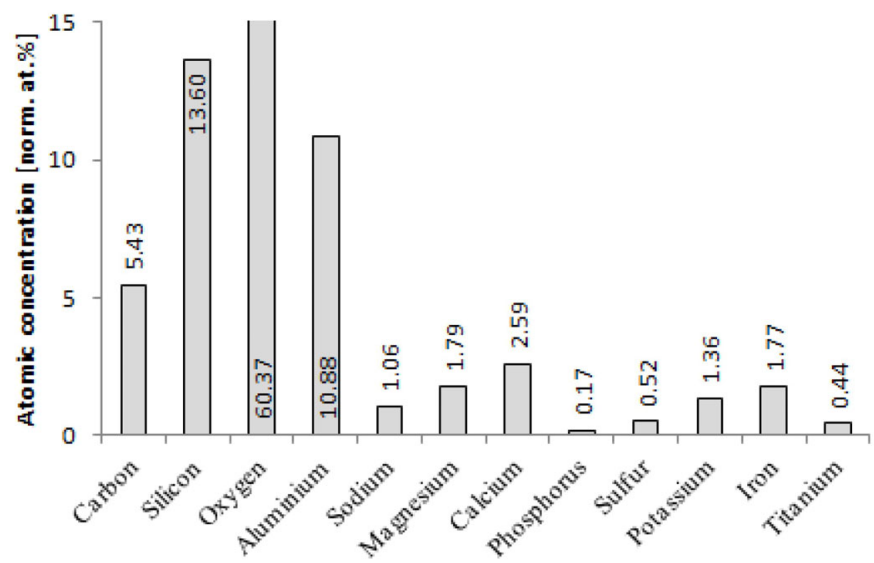

Fig. 5. Atomic concentration of elements in fly ash.

abundant is oxygen, about 60 at.\%, which forms silicone and aluminium oxides. Calcium, sodium, potassium and titanium were also recorded in the EDS spectrum (Fig. 4). The inset in Figure 4 shows SEM micrograph of fly ash particles, which are mainly spherical of diameter smaller than $5 \mu \mathrm{m}$.

\subsection{Light emission spectra}

In order to examine the influence of carbon dioxide concentration on the emission intensity of selected spectral lines in back discharge plasma, the pressure in the chamber was fixed to 1 bar, and supply voltage was set to $30 \mathrm{kV}$. The gas composition varied from pure nitrogen $\left(0 \% \mathrm{CO}_{2}\right)$ to pure carbon dioxide $\mathrm{CO}_{2}(100 \%)$. The intensity of spectral lines was measured after the discharge had reached a stable condition.

It is well know that in pure $\mathrm{N}_{2}$, the spectrum of discharge is dominated by the second positive system of $\mathrm{N}_{2}$, and weaker first negative system of $\mathrm{N}_{2}^{+}[5,6,11,12,24,25]$. Non-thermal plasma generated by electrical discharge at atmospheric pressure produces electrons and ions, which can be accelerated in electric field to high kinetic energy. Non-elastic collisions between energetic electrons and gaseous molecules will produce chemically active species. In electric discharge in $\mathrm{CO}_{2}$ at atmospheric pressure, the spectrum is more complex because many overlapping bands of $\mathrm{CO}_{2}, \mathrm{CO}$ and $\mathrm{C}_{2}$ systems are generated due to non elastic collisions between energetic electrons and $\mathrm{CO}_{2}$ molecules $[5,6,17]$. Although the emission of $\mathrm{CO}_{2}$ molecules cannot be observed in the investigated spectral range (because main emission lines are in the infrared range), the existence of $\mathrm{CO}_{2}$ may be detected indirectly, e.g. via detecting the emission of its dissociation products: $\mathrm{CO}$ or $\mathrm{C}_{2}$.

In $\mathrm{N}_{2}$ and $\mathrm{CO}_{2}$ mixture, besides the lines characteristic of $\mathrm{CO}_{2}$ and $\mathrm{N}_{2}$ pure gases, there can also be observed spectral lines of the reaction products of these gases.

In the case of back discharge, additional emission lines characteristic of elements and compounds volatilized from dielectric layer can be found in the emitted spectrum. In Figures $6-11$ the emission spectra of electrical discharges in $\mathrm{N}_{2}+\mathrm{CO}_{2}$ gas mixture for different $\mathrm{CO}_{2}$ concentrations are presented. The amount of $\mathrm{CO}_{2}$ varied from $0 \%$ (pure nitrogen), by $5 \%$ and $15 \%$ of $\mathrm{CO}_{2}$ in $\mathrm{N}_{2}$ to $100 \%$ (pure $\mathrm{CO}_{2}$ ). Results for air have also been presented for comparison.

The primary dissociation, excitation and ionization processes of the discharge occur in the needle zone. In pure nitrogen, only vibration sequences $\Delta v=$ $-4,-3,-2,-1,0$, of the $\mathrm{N}_{2}$ second positive system (SPS) were observed in the spectrum. In pure $\mathrm{CO}_{2}$ the following reactions can occur:

Vibration excitation dissociation:

$$
\mathrm{CO}_{2}\left(\nu^{*}\right)+\mathrm{e}^{-} \rightarrow \mathrm{CO}+\mathrm{O}+\mathrm{e}^{-}\left(E_{t h}=3.9 \mathrm{eV}\right)[18],
$$

Electron-impact ionization

$$
\mathrm{CO}_{2}+\mathrm{e}^{-} \rightarrow \mathrm{CO}_{2}^{+}+\mathrm{e}^{-}+\mathrm{e}^{-}\left(E_{t h}=13.8 \mathrm{eV}\right)[26] .
$$

Direct electron collision dissociation:

$$
\begin{gathered}
\mathrm{CO}_{2}+\mathrm{e}^{-} \rightarrow \mathrm{CO}+\frac{1}{2} \mathrm{O}_{2}+\mathrm{e}^{-}\left(E_{t h}=2.9 \mathrm{eV}\right)[27] \\
\mathrm{CO}_{2}^{*}+\mathrm{e}^{-} \rightarrow \mathrm{CO}+\mathrm{O}+\mathrm{e}^{-}\left(E_{t h}=5.45 \mathrm{eV}\right)[28]
\end{gathered}
$$

Figures 6 and 7 present the emission spectra of back discharge in pure $\mathrm{CO}_{2}$ and pure $\mathrm{N}_{2}$ taken from the layer zone for negative and positive polarity of the discharge electrode, respectively. In pure nitrogen, the SPS is incomplete. From five most intense line observed usually in the discharge, only three 313.6, 315.9, $357.69 \mathrm{~nm}$ of them appear. Faint $\mathrm{CN}$ violet system radiation with the maximum peak at $388.5 \mathrm{~nm}$ in pure nitrogen resulted probably from chemical reactions between $\mathrm{N}_{2}$ and carbon present in fly ash layer, following the process given by the equation: $\mathrm{A}+\mathrm{B}+\mathrm{X} \rightarrow \mathrm{AB}^{*}+\mathrm{X}$.

In pure $\mathrm{CO}_{2}$ at positive polarity of the discharge electrode, the emission lines of $\mathrm{CO}$, which is a dissociation product of $\mathrm{CO}_{2}$, have been observed in the discharge. Triplet band transition $d^{3} \Delta \rightarrow a^{3} \Pi(420-598 \mathrm{~nm})$ and Herzberg system transition $C^{1} \Sigma \rightarrow A^{1} \Pi$ (368-570 nm) have been recorded in the range of wavelengths investigated. Systems of positive and negative ions: $\mathrm{CO}_{2}^{+}$-Fox, 


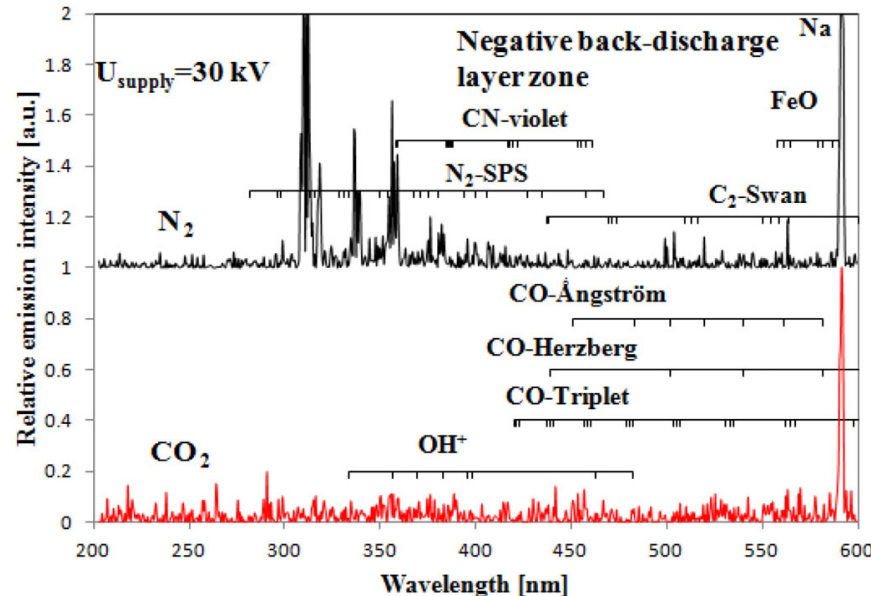

Fig. 6. Emission spectra of back discharge in pure $\mathrm{CO}_{2}$ and pure $\mathrm{N}_{2}$ taken from the layer zone for negative polarity of discharge electrode. Supply voltage $-30 \mathrm{kV}$.

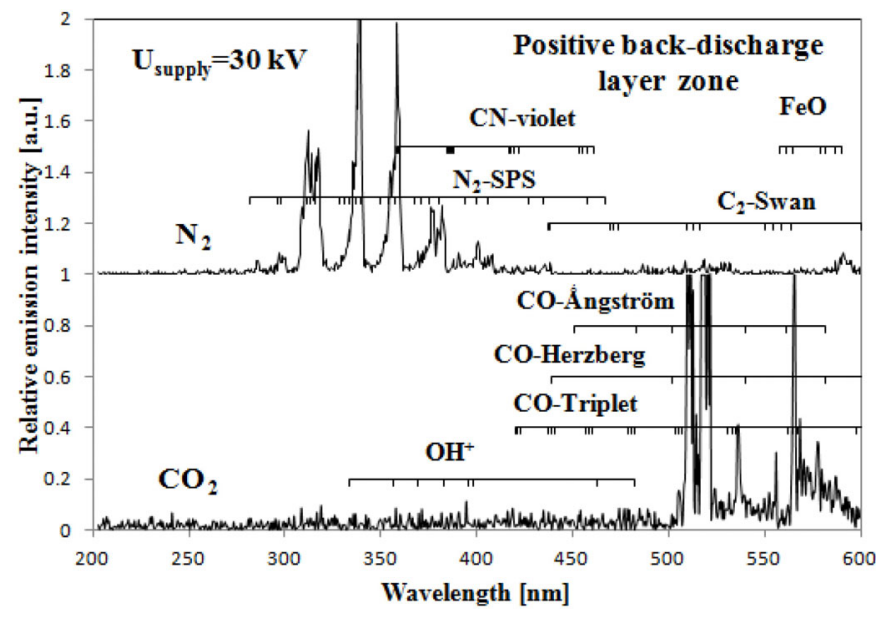

Fig. 7. Emission spectra of back discharge in pure $\mathrm{CO}_{2}$ and pure $\mathrm{N}_{2}$ taken from the layer zone for positive polarity of discharge electrode. Supply voltage $30 \mathrm{kV}$.

Duffendack and Barker's system, transition $A^{2} \Pi \rightarrow X^{2} \Pi$ (287-416 nm) and $\mathrm{CO}^{+}$, the Ångström system, transition $B^{1} \Sigma \rightarrow A^{1} \Pi(412-581 \mathrm{~nm})$, as products of gas ionization, have also been recorded. The typical green $\mathrm{C}_{2}$ emission line does not appear in the discharge of positive polarity at the needle electrode but only $\mathrm{CO}$ emission systems are more intense.

In pure $\mathrm{CO}_{2}$, for negative polarity of the discharge electrode, there lack light emission in the visible spectrum due to electronegativity of this gas, which attaches electrons, quenching by this way the discharge processes. Only weak CO emission can be recorded at the noise level and a strong $\mathrm{Na}$ line at $589.5 \mathrm{~nm}$. Sodium is probably ionized directly in fly ash layer due to electron and negative $\mathrm{CO}_{2}$ ions bombardment. The $\mathrm{CO}_{2}$ dissociation is mainly due to the vibrational excitation caused by electron impact. The analysis of our experimental spectra confirm that $\mathrm{CO}_{2}$ dissociations generates, directly or indirectly, the formation of $\mathrm{CO}$ and $\mathrm{O}$ in excited or ground states.
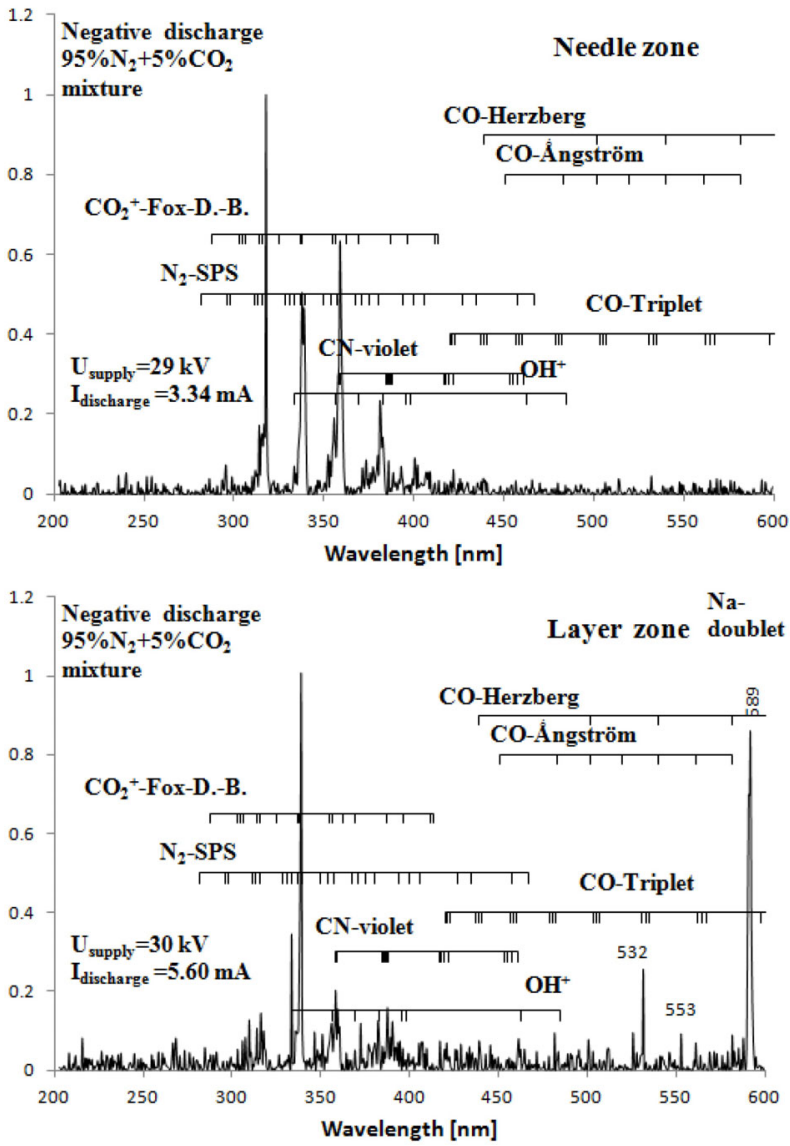

Fig. 8. Emission spectra of back discharge in $95 \% \mathrm{~N}_{2}+5 \%$ $\mathrm{CO}_{2}$ mixture at the needle zone and crater (layer) zone, for negative polarity of the discharge electrode. Supply voltage $30 \mathrm{kV}$. Thickness of fly ash layer-5 mm.

Because of fly ash elemental composition, the spectral lines characteristic of fly ash compounds appear also in these gases (cf. Figs. 4 and 5). For example, $\mathrm{C}_{2}$ band appears in pure nitrogen due to excitation of the carbon molecules, which are volatilized from fly ash layer (carbon concentration in fly ash about 5 at.\%). Strong sodium line both in $\mathrm{CO}_{2}$ and $\mathrm{N}_{2}$ (cf. Figs. 7 and 8; Na concentration $\sim 1$ at. \%) can also be noticed.

Electric discharge in a mixture of $\mathrm{N}_{2}+\mathrm{CO}_{2}$ results in many additional spectral lines as an effect of plasma chemical reactions between molecules of these gases and additionally with elements and compounds from fly ash layer. Only a small admixture of carbon dioxide to nitrogen was enough to change the emission spectra. Besides formerly discussed lines, the $\mathrm{CN}$ violet $\left(B^{2} \Sigma^{+} \rightarrow X^{2} \Sigma^{+}\right)$ and red $\left(A^{2} \Pi \rightarrow X^{2} \Sigma^{+}\right)$systems appear in the emission spectra of back discharge plasma generated in $\mathrm{N}_{2}+\mathrm{CO}_{2}$ gas mixture. The $\mathrm{CN}$ radicals are formed from $\mathrm{CO}_{2}$ after its dissociation and reaction of $\mathrm{C}_{2}$ with $\mathrm{N}_{2}$.

In the spectrum of back discharge in $95 \% \mathrm{~N}_{2}+5 \% \mathrm{CO}_{2}$ mixture at atmospheric pressure the nitrogen SPS is still dominant in the needle zone but this emission is suppressed in the crater zone, whereas molecular bands of $\mathrm{CO}, \mathrm{C}_{2} \quad\left(\mathrm{C}_{2}\right.$-Swan system transition $A^{3} \Pi_{g} \rightarrow X^{\prime} \Pi_{u}$ 

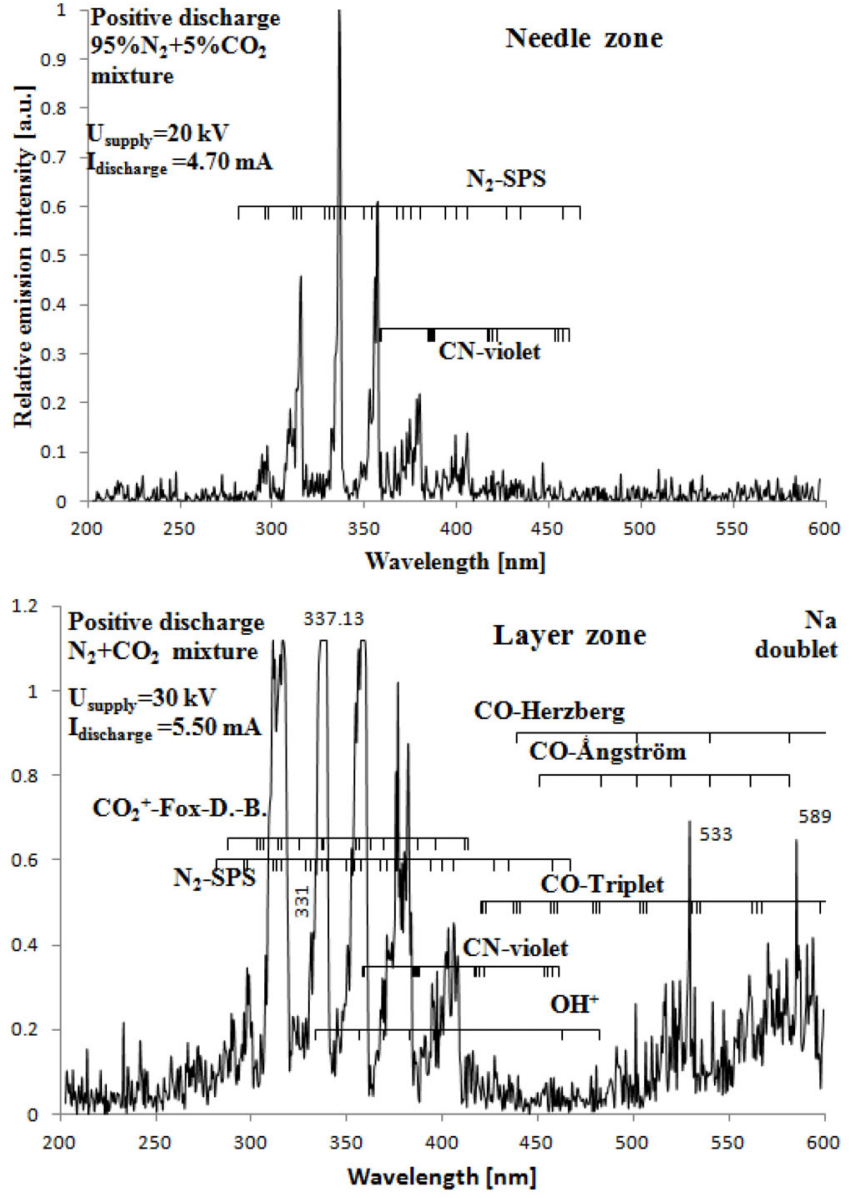

Fig. 9. Emission spectra of back discharge in $95 \% \mathrm{~N}_{2}+5 \%$ $\mathrm{CO}_{2}$ mixture at the needle and crater (layer) zone, for positive polarity of the discharge electrode. Supply voltage $+30 \mathrm{kV}$. Thickness of fly ash layer- $5 \mathrm{~mm}$.

(436-600 nm)) and CN are higher in this zone for both polarities (cf. Figs. 8 and 9). The emission intensity of $\mathrm{CO}$, which is dissociation product of $\mathrm{CO}_{2}$, was weaker in $\mathrm{N}_{2}+\mathrm{CO}_{2}$ mixture than in pure carbon dioxide. When a small amount of $\mathrm{CO}_{2}$ was added to nitrogen, a strong emission bands from $\mathrm{C}_{2}$ radicals were observed in the discharge. The correlation between carbon monoxide emission intensity and $\mathrm{C}_{2}$ emission had not been noticed. It was also noticed that for discharge in pure carbon dioxide, the emission of $\mathrm{C}_{2}$ was below noise level, but in $\mathrm{N}_{2}+\mathrm{CO}_{2}$ mixture strong emission bands from $\mathrm{C}_{2}$ radical were observed. Also the oxygen emission lines, as a possible product of $\mathrm{CO}_{2}$ dissociation is absent in the spectra.

In emission spectra shown in Figures 10 and 11, intense emission of $\mathrm{TiO}$ (Orange-system: $559 \mathrm{~nm}, 562 \mathrm{~nm}$, $566 \mathrm{~nm}$ ), $\mathrm{FeO}$ lines (positive polarity) and $\mathrm{Na}$ (negative polarity) originating from fly ash layer can also be observed. Light emission by particles from fly ash layer is weaker than the intensity of emission by molecular gases. Emission of other elements and compounds in the layer zone, like Al (452 nm, $317 \mathrm{~nm}$ ), Si 2 (458 nm, $462 \mathrm{~nm}), \mathrm{Na}_{2}$ $(336 \mathrm{~nm}, 331 \mathrm{~nm}), \mathrm{Si}_{2} \mathrm{O}(448 \mathrm{~nm}), \mathrm{MgO}$ (Green-system: $499 \mathrm{~nm}, 500 \mathrm{~nm}, 494 \mathrm{~nm})$, Ca (559.8 nm, $393.4 \mathrm{~nm})$ have

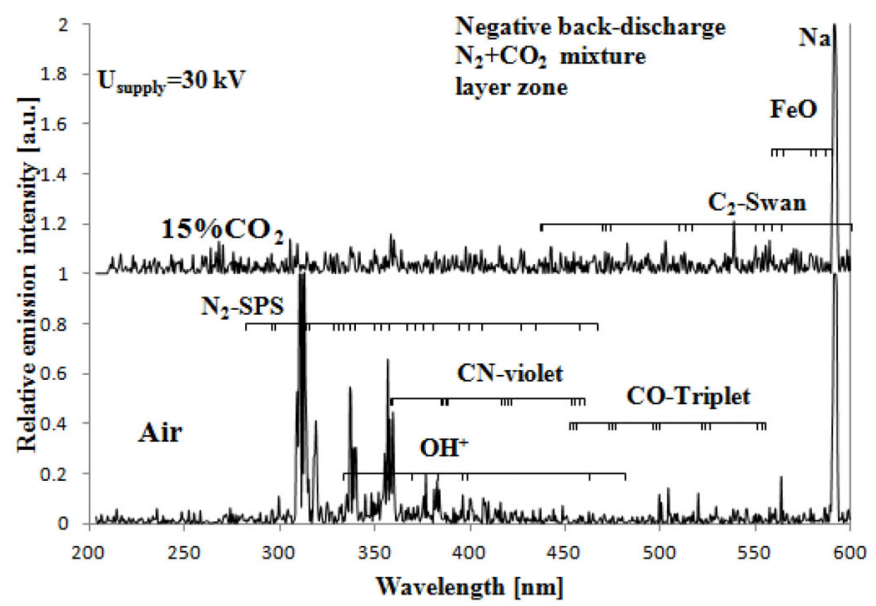

Fig. 10. Comparison of back discharge emission spectra in $15 \% \mathrm{CO}_{2}+85 \% \mathrm{~N}_{2}$ and in air for negative polarity of discharge electrode, taken from in the layer zone. Supply voltage $-30 \mathrm{kV}$.

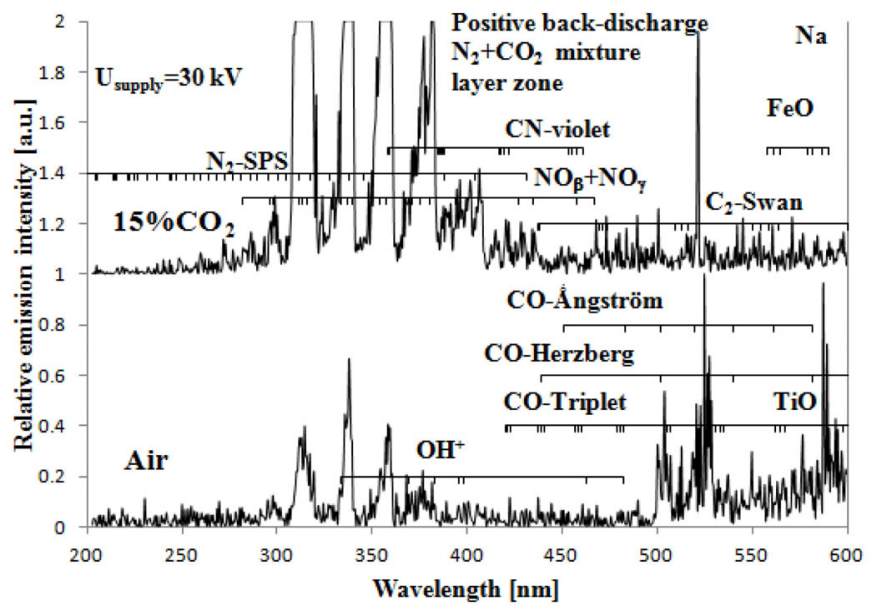

Fig. 11. Comparison of back discharge emission spectra in $15 \% \mathrm{CO}_{2}+85 \% \mathrm{~N}_{2}$ and in air for positive polarity of discharge electrode, taken from in the layer zone. Supply voltage $+30 \mathrm{kV}$.

been also recorded for positive polarity of discharge electrode. The emission lines from $\mathrm{TiO}$ transitions at $567 \mathrm{~nm}$, $\mathrm{Na}$ at $591 \mathrm{~nm}$, and $\mathrm{FeO}$ at $546 \mathrm{~nm}$, which appear in the layer zone depend on polarity of the discharge electrode. The emission intensity of $\mathrm{Ca}, \mathrm{TiO}, \mathrm{Si}_{2}, \mathrm{MgO}, \mathrm{Na}_{2}$ is nearly zero at the needle electrode. The observed molecular transitions and their wavelength ranges are listed in Table 1.

When the amount of $\mathrm{CO}_{2}$ increases, back discharge starts to differ significantly from that at low $\mathrm{CO}_{2}$ content. The emission spectra in $15 \% \mathrm{CO}_{2}+85 \% \mathrm{~N}_{2}$ gas mixture for negative and positive polarity of the discharge electrode are shown in Figures 10 and 11, respectively. The intensity of SPS bands depends on $\mathrm{CO}_{2}$ concentration, and decreases when the concentration of $\mathrm{CO}_{2}$ increases. It indicates that vibrationally excited $\mathrm{N}_{2}$ molecules participate in the dissociation and ionization reactions. For negative polarity, $\mathrm{CO}_{2}$ quenches totally the $\mathrm{N}_{2}$ SPS emission. 
Table 1. Spectral lines observed in $\mathrm{N}_{2}+\mathrm{CO}_{2}$ gas mixture during back discharge (these molecular bands are marked in the spectra shown in Figs. 8 and 9).

\begin{tabular}{cccccc}
\hline Species & System name & Transition & $\begin{array}{c}\text { Wavelength } \\
\text { range }[\mathrm{nm}]\end{array}$ & Pos. & Neg. \\
\hline $\mathrm{N}_{2}$ & Secound Positive System & $C^{3} \Pi_{u} \rightarrow B^{3} \Pi_{g}$ & $290-466$ & + & + \\
$\mathrm{CN}$ & Violet System & $B^{2} \Sigma \rightarrow A^{2} \Pi$ & $335-360$ & + & + \\
$\mathrm{CO}$ & Fourth Positive System & $A^{1} \Pi \rightarrow X^{1} \Sigma$ & $209-290$ & + & - \\
$\mathrm{CO}_{2}^{+}$ & Fox, Duffenduck and Barker's system, & $A^{2} \Pi \rightarrow X^{2} \Pi$ & $313-416$ & - & + \\
$\mathrm{C}_{2}$ & Swan System & $A^{3} \Pi_{g} \rightarrow X^{\prime 3} \Pi_{u}$ & $437-558$ & + & - \\
$\mathrm{FeO}$ & Orange System & $c^{1} \Phi \rightarrow a^{1} \Delta$ & $558-590$ & + & - \\
$\mathrm{TiO}$ & Orange system- $\beta$ & $c^{1} \Phi \rightarrow a^{1} \Delta$ & $584-595$ & + & - \\
$\mathrm{N}_{2}^{+}$ & 1-st Negative & $B^{2} \Sigma_{u}^{+} \rightarrow X^{2} \Sigma_{g}^{+}$ & $293-586$ & + & + \\
$\mathrm{OH}^{+}$ & 3565 A system & $A^{3} \Pi \rightarrow X^{3} \Sigma^{-}$ & $333-398$ & + & - \\
$\mathrm{Na}$ & Sodium doublet & $3 p \rightarrow 3 s$ & 589.0 & - & + \\
\hline
\end{tabular}

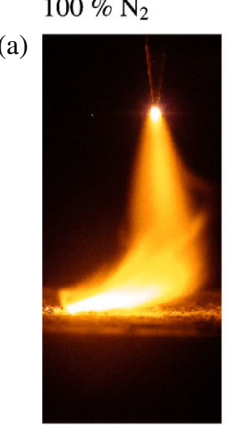

$\mathrm{t}=1 \mathrm{~s}$

(b)

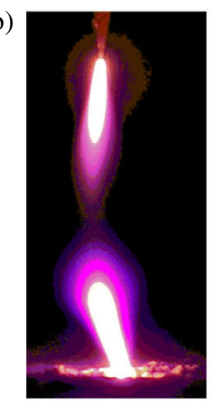

$\mathrm{t}=1 \mathrm{~s}$

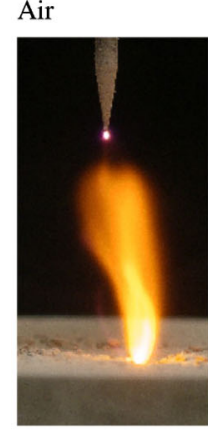

$\mathrm{t}=1 / 10 \mathrm{~s}$

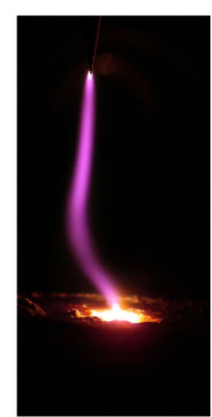

$\mathrm{t}=10 \mathrm{~s}(?)$
$5 \% \mathrm{CO}_{2}+\mathrm{N}_{2}$

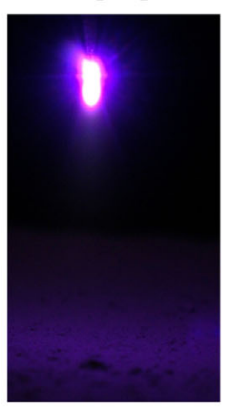

$\mathrm{t}=15 \mathrm{~s}$

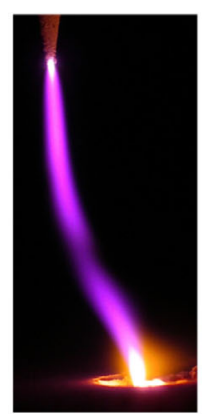

$\mathrm{t}=1 / 10 \mathrm{~s}$

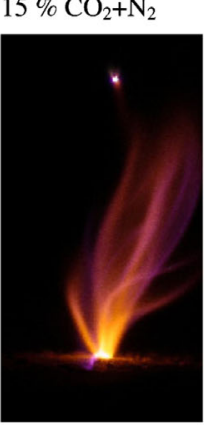

$100 \% \mathrm{CO}_{2}$

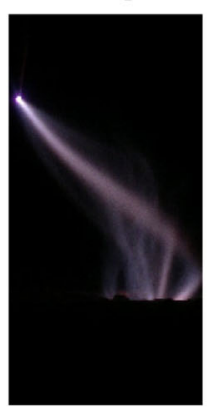

$\mathrm{t}=0.5 \mathrm{~s}$

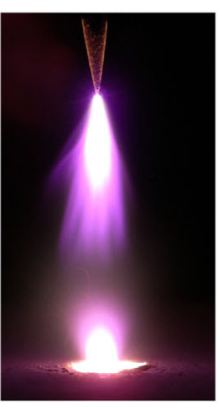

$\mathrm{t}=1 \mathrm{~s}$

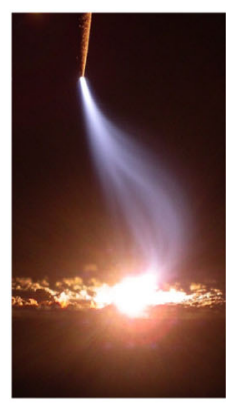

$\mathrm{t}=1 / 4 \mathrm{~s}$

Fig. 12. Photographs of back arc discharge between the electrodes as a function of carbon dioxide concentration in nitrogen. Supply voltage $\pm 30 \mathrm{kV}$, (a) negative polarity of needle electrode, (b) positive polarity of needle electrode. Exposure beneath each photograph.

Because $\mathrm{O}$ as electronegative gas (product of $\mathrm{CO}_{2}$ dissociation) reduces the number and energy of free electrons by their attachment after collision, the deficit of electrons in the ionization zone prevents $\mathrm{N}_{2}$ ionization. For positive polarity, $\mathrm{N}_{2}$ SPS is probably generated due to nitrogen thermal ionization in the craters. These results have been compared with those obtained in air [29]. In that work, for both polarities of the discharge electrode, the SPS has been recorded, although for positive, the emission of $\mathrm{CO}$ and compounds volatilized from the layer are much intense than SPS.

Photographs of back arc discharges between the electrodes for various carbon dioxide concentration in nitrogen and for air are shown in Figure 12. These photographs indicate qualitatively that $\mathrm{N}_{2}$ SPS is dominant for posi- tive polarity because of violet glow of the discharge, while for negative, except pure $\mathrm{CO}_{2}$, yellow glow indicates the emission of sodium from fly ash layer. For pure $\mathrm{CO}_{2}$, faint while glow indicates $\mathrm{CO}$ emission.

Relative emission intensity for various molecules vs. carbon dioxide concentration in gas mixture is shown in Figure 13. The addition of small amount of $\mathrm{CO}_{2}(5$ and $15 \%$ ) leads to a significant increase in the intensity of ionized gaseous molecules. For example:

- The emission intensity of nitrogen $\mathrm{N}_{2}$-SPS $\left(C^{3} \Pi_{u} \rightarrow\right.$ $B^{3} \Pi_{g}$ transition) increases, due to an increase in the number of electrons ionizing the gaseous molecules. With the concentration of nitrogen in gas mixture decreasing, the emission intensity also decreases. 


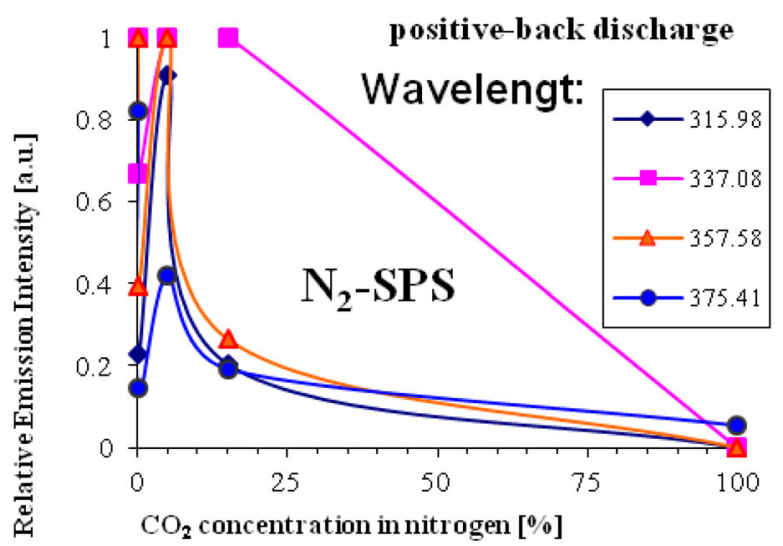

(a)

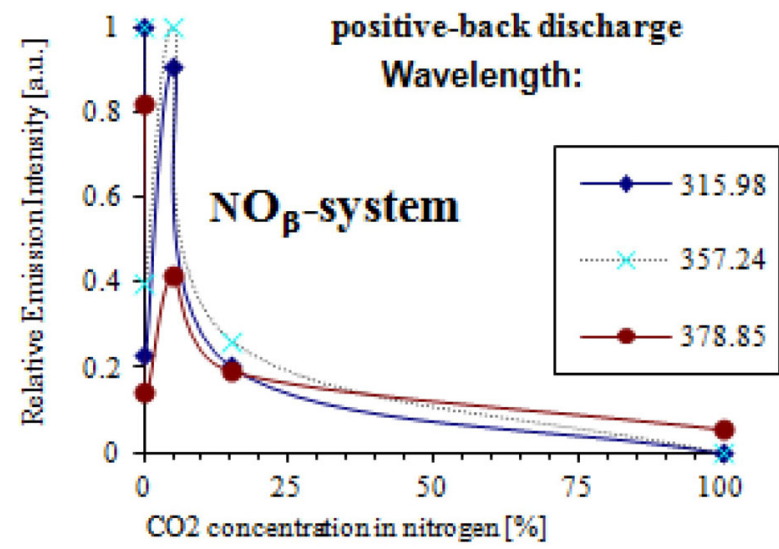

(c)

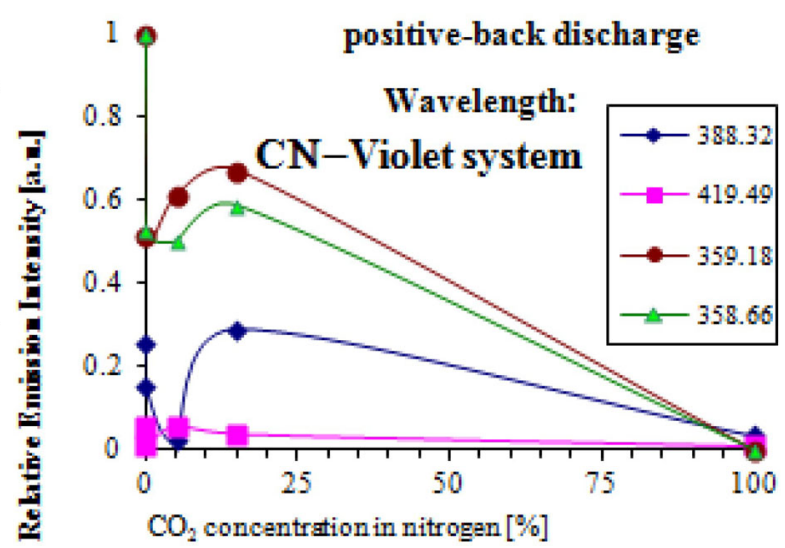

(b)

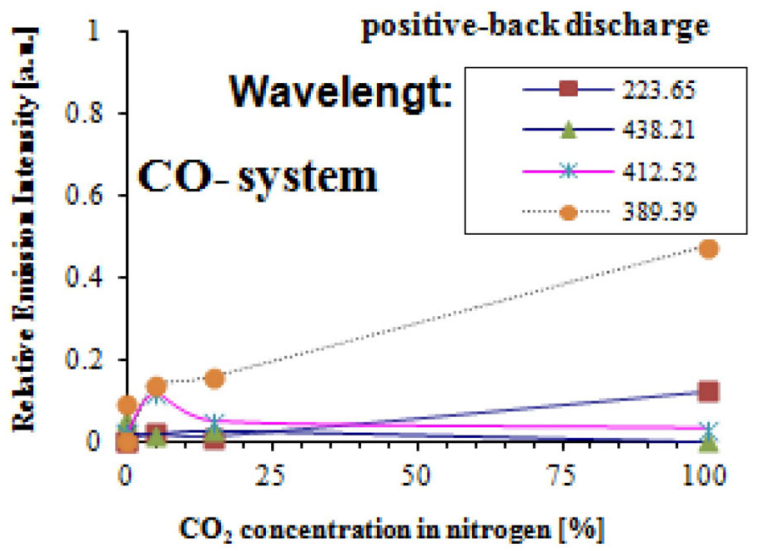

(d)

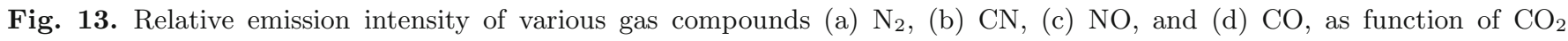
concentration at atmospheric pressure for positive polarity of the discharge electrode. Supply voltage $30 \mathrm{kV}$.

- The emission intensity of $\mathrm{NO}_{\beta}$ initially increases, as an effect of decomposition of $\mathrm{CO}_{2}$, and reaction with nitrogen present in the gas mixture. The maximum intensity occurred at the nitrogen concentration of about $5 \%$. In air and flue gases, an increase of $\mathrm{NO}_{\beta}$ also results from the presence of oxygen in the gas [5].

- The maximum intensity of CN emission was observed when the concentrations of nitrogen was relatively high, and the concentration of carbon dioxide are equal and lower than $15 \%$ (Fig. 13). This indicates that two mechanisms of the production of $\mathrm{CN}$ are possible: nitrogen can react with carbon volatilized from fly ash, and nitrogen can react with products of dissociation of $\mathrm{CO}_{2}$.

- Carbon oxide lines, as the product of dissociation of $\mathrm{CO}_{2}$ have also been observed. The measured $\mathrm{CO}$ lines intensities were increased as the $\mathrm{CO}_{2}$ concentration increased.

\section{Conclusions}

Back discharge plasma in the presence of fly ash on passive electrode has been studied with respect to optical emission spectra. The plasma column created by electrical discharge was studied in two characteristic zones: the needle-tip zone (in the vicinity of the needle electrode tip), and the crater zone (close to the crater in dielectric layer). Back discharge plasma at atmospheric pressure has been investigated in order to analyze the influence of carbon dioxide concentration on plasma in $\mathrm{N}_{2}+\mathrm{CO}_{2}$ gas mixture, two main components of flue gases in coal fired power plants.

The addition of a small amount of $\mathrm{CO}_{2}$ to $\mathrm{N}_{2}$ had resulted in significant quenching of back-arc discharge. By studying the intensities of emission lines during back discharge, information has been obtained on ionization and excitation processes. It can be concluded that in the crater zone, the thermal excitation processes are dominating.

A careful spectroscopic analysis in the optical ranges revealed the $\mathrm{CN}, \mathrm{N}_{2}$ and $\mathrm{C}_{2}$ molecular emission systems. Adding $\mathrm{CO}_{2}$ to nitrogen reduced the intensity of ionizednitrogen lines. The emission lines and bands of $\mathrm{CN}$ molecules also appeared and increased with increasing $\mathrm{CO}_{2}$ concentration up to $85 \%$ (Fig. 13b). The $\mathrm{CN}$ molecules appeared due to dissociation of $\mathrm{CO}_{2}$ in the electrically generated plasma, and reaction of carbon with 
nitrogen. The presence of $\mathrm{FeO}$ and $\mathrm{TiO}$ lines in the spectrum indicates that these species present in fly ash layer were volatilized during the back-arc discharge. The intensity of emission lines of $\mathrm{Na}$ (one of the fly ash compounds) is higher for negative polarity than for positive.

\section{Author contribution statement}

All the authors have contributed equally to the paper.

The work has been supported by the by Institute of Fluid Flow Machinery of the Polish Academy of Sciences.

\section{References}

1. N. Koshino, Y. Yoshitake, N. Hayakawa, H. Okubo, Partial discharge and breakdown characteristics of $\mathrm{CO}_{2}$-based gas mixtures as $\mathrm{SF}_{6}$ substitutes. in Gaseous Dielectrics $X$, edited by L.G. Christophorou, J.K. Olthoff, P. Vassiliou (Springer, 2004)

2. H. Nowakowska, M. Jasiński, J. Mizeraczyk, Eur. Phys. J. D 54, 511 (2009)

3. A. Krupa, Eur. Phys. J. D 54, 265 (2009)

4. B. Hrycak, M. Jasiński, J. Mizeraczyk, Eur. Phys. J. D 60 , $609(2010)$

5. T. Czech, A.T. Sobczyk, A. Jaworek, A. Krupa, J. Electrostatics 70, 269 (2012)

6. A. Jaworek, A. Sobczyk, E. Rajch, J. Phys.: Conf. Ser. 142, 012040 (2008)

7. A.H. Timmermans, J. Jonkers, A.J. Thomas, A. Rodero, M.C. Quintero, A. Sola, A. Gamero, A.M. van der Mullen, Spectrochimica Acta Part B 53, 1553 (1998)

8. J.E. Harry, Q. Yuan, Int. J. Electronics 87, 1105 (2000)

9. A. Denat, N. Bonifaci, M. Nur, IEEE Trans. EI 5, 382 (1998)

10. M. Benmansour, M. Nikravech, D. Morvan, J. Amouroux, J. Chapelle, J. Phys. D 37, 2966 (2004)

11. C. Rond, A. Bultel, P. Boubert, B.G. Chéron, Chem. Phys. 354, 16 (2008)
12. P.-H. Su, Z. Yi-Min, Y. Shu, J. Electrostatics 66, 193 (2008)

13. Kazuo Shimizu, Shusuke Saeki, Go Yamada, Tetsuuji Oda, Sci. Technol. Adv. Mater. 2, 577 (2001)

14. Y. Manabe, T. Shimazaki, Trans. Dielectr. Electr. Insul. 11, 631 (2004)

15. A.H. Timmermans, J. Jonkers, A.J. Thomas, A. Rodero, M.C. Quintero, A. Sola, A. Gamero, A.M. van der Mullen, Spectrochemica Acta Part B 1553 (1998)

16. T. Czech, A.T. Sobczyk, A. Jaworek, Eur. Phys. J. D 65, 459 (2011)

17. T. Czech, A.T. Sobczyk, A. Jaworek, A. Krupa, E. Rajch, Eur. Phys. J. D 67, 1 (2013)

18. M. Janda, V. Martišovitš, M. Morvová, Z. Machals, K. Hensel, Eur. Phys. J. D 45, 309 (2007)

19. M. Jasiński, J. Mizeraczyk, Z. Zakrzewski, Czechoslovak J. Phys. 56, B787 (2006)

20. R.W.B. Pearse, A.G. Gaydon, The Identification of Molecular Spectra (Chapman and Hall, London, 1963)

21. A.R. Striganov, Svetnickij, Spectral lines of neutral and ionized atoms, Moskva Atomizdat. (1977) Izd. Nauka, Moskva (1966) (in Rusian)

22. G.J.M. Hagelaar, L.C. Pitchford, Plasma Sources Sci. Technol. 14, 722 (2005)

23. M. Goldman, A. Goldman, Corona discharges, Gaseous Electronics (American Press Inc., 1978), Vol. 1

24. A.S. Kirillov, J. Quant. Spectrosc. Radiat. Transfer 112, 2164 (2011)

25. S. Masuda, A. Mizuno, J. Electrostatics 4, 35 (1977/1978)

26. Y. Itikawa, J. Phys. Chem. Ref. Data 31, 749 (2002)

27. V.D. Rusanov, A.A. Fridman, G.V. Sholin, Sov. Phys. Usp. 24, 447 (1981)

28. F. Poncin-Epaillard, M. Aouinti, Plasmas Polymers 7, 1 (2002)

29. T. Czech, A.T. Sobczyk, A. Jaworek, Eur. Phys. J. D 65, 459 (2011)

Open Access This is an open access article distributed under the terms of the Creative Commons Attribution License (http://creativecommons.org/licenses/by/4.0), which permits unrestricted use, distribution, and reproduction in any medium, provided the original work is properly cited. 